\title{
Explorations in the Taxonomy of Behavior Settings
} Analysis of Dimensions and Classification of Settings ${ }^{1}$

\author{
Richard H. Price ${ }^{2}$ \\ University of Michigan \\ Roger K. Blashfield \\ Pennsylvania State University
}

Two studies are reported which examine the entire population of behavior settings ( $\mathrm{N}=455)$ measured on 43 variables in a small midwestern town. Study $I$ reports the results of a factor analysis of 43 variables measured across the entire population of settings. Results of Study I indicate that age, sex, role of setting inhabitants, duration, and various behavior patterns all constitute important underlying dimensions of behavior settings. Study II reports the results of a cluster analysis of the 455 settings which yielded 12 distinct behavior setting types. Implications of the present study for (a) the phenomenon of personenvironment congruence, (b) a theory of community settings, and (c) research on community-based social settings were discussed.

The recent resurgence of interest in the power of various kinds of social settings to influence behavior has been accompanied by a shift in the focus of behavioral scientists from the individual characteristics of persons to efforts aimed at characterizing social situations or settings (Barker, 1968; Cowen, 1973; Craik, 1973; Frederiksen, 1972; Mischel, 1973; Moos, 1973; Price, 1974; Price \& Bouffard, 1974; Price \& Moos, 1975; Sells, 1963; Wicker, 1972).

\footnotetext{
1 The research reported in this paper was supported in part by NIMH Special Fellowship FO3 MH4714-01 to the first author while on leave at the Social Ecology Laboratory, Stanford University. The authors wish to extend their most sincere appreciation to Roger $G$. Barker and Paul Gump, who were kind enough to furnish us with the Behavior Setting Survey data that formed the basis of this paper. Thanks also are due to Professor Dan Ragle who aided with many of the details of copying and organization of information relevant to the survey. Finally, the authors wish to thank Roger G. Barker, John Monahan, Rudolf Moos, and Allen Wicker for their comments on an earlier draft of this paper.

${ }^{2}$ Requests for reprints should be sent to Dr. Richard H. Price, Department of Psychology, 529 Thompson, University of Michigan, Ann Arbor, Michigan 48104.
} 
One important approach to understanding the characteristics of social settings is the development of setting taxonomies or classifications. Cowen (1973) expresses this concern in his recent review of social and community interventions: "To understand the effects of settings on growth requires that we first develop systematic frameworks for describing settings - something we currently lack" (p. 434).

In addition, Blashfield (1973) has pointed out that the construction of taxonomies can serve several important purposes. Taxonomies can provide the basis for a nomenclature for the entities under study. Taxonomic classification also facilitates the description of similarities and differences among the entities studied. Further, taxonomies may allow the prediction of measures on variables not used in forming the classification itself. Finally, classifications may provide the basis for theoretical concepts in a given field. Hempel (1965) has argued that classification may be thought of as a process of scientific concept formation where the classes derived represent initial organizing concepts in the field of study.

There are at least three major issues which must be confronted in developing a workable taxonomy of settings. First, the settings to be classified must be reliably identified. Second, the selection and summary of variables or dimensions used to describe the entity must be accomplished. Third, a decision must be made concerning how settings will be sampled and classified once they have been defined and described.

Barker (1968) has considered the first question of how environmental units may be defined in some detail. His solution to this problem is to offer the concept of behavior setting. Behavior settings are naturally occurring phenomena and have not been created by the experimenter for scientific purposes. Examples of behavior settings might be the junior high school play, an English class, a basketball game, or a drug store. The use of behavior settings as a fundamental environmental unit provides a number of advantages. First, behavior settings can be reliably identified according to explicit criteria (Barker, 1968). A second advantage of behavior setting as a unit of analysis is that it includes both physical and behavioral components (Wicker, 1972). The advantage of behavior settings is that they are multidimensional phenomena encompassing physical, temporal, and behavioral aspects of the immediate environment of individuals. Thus, as a basic environmental unit, the behavior setting appears to deal with many of the difficulties associated with the problem of setting definition.

The second major problem in the development of setting taxonomies has to do with the question of identifying and summarizing the major variables characterizing settings. The selection of variables to describe the object of study is a highly subjective enterprise (Bailey, 1973); nevertheless, a good deal of attention has been paid to this question (Astin, 1962; Sells, 1963). The selection 
of dimensions to characterize environmental units will certainly depend on the specific nature of the unit under study and the theoretical assumptions and interests of the investigator. It is reasonable to assume, however, that the broader the range of variables selected, the more likely that adequate environmental description will be achieved.

Barker (1968) and his associates have developed a large number of variables designed to measure salient characteristics of behavior settings, including system characteristics, behaviors which predominate in the setting, demographic and role characteristics of setting inhabitants, population size, setting duration, and frequency. These variables provide an extremely broad multidimensional basis for the isolation of important behavior setting attributes.

The third problem in developing a taxonomy of settings involves the sampling of settings from some larger population and its classification into a number of relatively homogeneous and distinct groups or classes. The behavior setting surveys done by Barker (1968) and his colleagues lend themselves quite well to the problem. These surveys define an entire town as a naturally occurring ecologically defined population of behavior settings. Such a definition provides a large number and variety of settings for classification. Furthermore, once the population of settings has been defined in this way, either it may be sampled randomly with some assurance that the sample is representative of the population or the entire population of settings may be classified using empirical procedures. Empirical classifications usually employ multivariate methods that form homogeneous groups of entities on the basis of similarities and differences among the entities with respect to measured characteristics. The basic goal of these procedures is the formation of groups, which maximizes the interclass differences and intraclass similarity.

\section{Purpose}

The studies reported here examine the entire population of behavior settings in a small midwestern town surveyed by Barker and his colleagues. The first study develops a set of behavior setting attributes by examining the broad range of variables used to characterize behavior settings. Forty-three variables are examined by factor analysis across the 455 behavior settings measured in the town in Barker's 1968-69 behavior setting survey. The purpose of the factor analysis is to isolate major dimensions upon which behavior settings vary and, therefore, to derive a tentative taxonomy of behavior setting attributes.

The second study reports the results of a cluster analysis of the 455 behavior settings in the town. The purpose of the second study is to develop a tenta- 
tive empirical classification of behavior settings based on the similarities and differences among settings with respect to the variables measured.

These two studies also provide different analytic perspectives on the data matrix formed by the 455 settings, each measured on 43 descriptive variables. Since this data matrix offers one approach to describing the structure of the town itself, the results should provide in formation, not only about behavior setting attributes and classification, but also about the structure of a small midwestern town.

\section{STUDY I}

\section{Method}

\section{Description of the Town}

The sample of behavior settings analyzed in the present study was drawn from a small midwestern town with a population of 628 persons in 1968-69. This town was one of six in the 1959 and 1969 surveys conducted by Barker and his colleagues. All six towns are within a county having a population of 11,949 persons in 1969. The county is largely rural in nature and also contains the county seat ("Midwest") which has been surveyed in a number of research reports by Barker and his colleagues (Barker \& Gump, 1964; Barker 1968). The behavior setting survey that forms the basis of the current research was obtained in 1969. A total of 455 behavior settings were surveyed which constituted the entire population of behavior settings in the town.

\section{Classes of Variables Measured for Each Behavior Setting}

Eight major classes of variables were included in the present analysis. The first class of variables measuring characteristics of behavior settings was the class of authority system (CAS) to which the setting belongs. The definitions of authority systems are based on characteristics described by Warriner and Prather (1965). Each behavior setting was classified as belonging to one of the five following authority systems: private enterprise, churches, government agencies, schools, and voluntary organizations.

The second major class of variables used to describe behavior settings were action patterns. Action patterns are rated in terms of the total amount of occupancy time in the setting devoted to that pattern (Barker, 1968). Eight action patterns were included in the present analysis. They were: art, business, education, government, nutrition, physical health, recreation, and religion. 
The third, fourth, and fifth categories of behavior setting characteristics used in the present study had to do with the age and sex characteristics of three classes of roles of individuals participating in behavior settings, those of member, performer, and target; Members and performers are differentiated in terms of the degree to which they are centrally involved in a setting. Typically members may serve as onlookers, invited guests, audience members, or customers in a setting. Thus, the distinction between members and performers reflects the degree of involvement and responsibility a person has in the setting. Target individuals, on the other hand, are those individuals for which the setting is especially planned or intended. For example, Cub Scouts is especially planned for males aged 8 years to 10 years 11 months. Each behavior setting was characterized by the presence or absence of various age and sex characteristics of members, performers, and target groups.

The sixth class of variables analyzed in the current study was the size of the behavior setting in terms of the number of individuals in the behavior setting per occurrence. There were two variables included in this class. The first index was the number of different members who enter the setting each time it occurs. The number of performers per occurrence was measured as the second index.

The seventh class of variables included in the present analysis was that of the duration of the behavior setting. Three variables were included in this class. The first was the average number of hours of stay in the setting per member. The second variable was the average number of hours of stay per setting for a performer. Finally, the average duration per occurrence of the setting was included in this class.

The eighth and final class of variables was that of the frequency of occurrence of the behavior setting, which was measured as the number of occurrences of the setting during one calendar year.

Thus, eight domains of setting characteristics were included in the present analysis. These eight domains provide a broad range of setting characteristics including authority system membership; the action patterns of the individuals within the behavior setting; the average background characteristics of members, performers, and target individuals in the behavior settings; the population of the behavior setting for both members and and performers; its duration; and its frequency per year.

\section{Method of Analysis}

The 43 variables described above were intercorrelated across the 455 behavior settings surveyed in the town. The resulting intercorrelation matrix was subjected to a factor analysis. The method of factoring was a principal components analysis with the largest off diagonal correlations used to estimate communalities followed by an orthogonal varimax rotation (Nie, Bent, \& Hull, 1970). 


\section{Results and Discussion}

\section{Factor Analysis of Behavior Setting Characteristics}

A principal component analysis produced 13 factors which had Eigenvalues greater than 1.0. These 13 factors, their Eigenvalues, and the percentage of variance accounted for by each of the factors is given in Table I. Application of the SCREE test (Cattell, 1966) indicated that 9 of these factors should be selected for interpretation. Examination of Table I makes it clear that the variables used to describe behavior settings appear to produce a relatively large number of discrete factors. The 9 interpretable factors account for $62.2 \%$ of the total variance. Table I also presents the factor loadings of the 43 variables describing behavior settings on the 9 interpretable factors. Only loadings having an absolute value greater than .30 have been included. Examination of the variables loading on each factor suggests that they are relatively unambiguous and easily interpretable.

\section{Description of Factorial Attributes of Behavior Settings}

The first factor obtained, adult members and targets, had high loadings on variables indicating that setting members were adults or elderly persons and the settings were intended for adult targets. In addition, performers tended to be elderly and male. Finally, negative loadings on the education action pattern and on the school authority system variable suggests that this factor involves nonschool-sponsored behavior.

Factor 2, religion versus government, emerged as a bipolar factor. The government action pattern variable and the school authority system variable both had high loadings on this factor. However, strong negative loadings were obtained for the church authority system variable and the religion action pattern variable. Thus, a second underlying dimension of behavior settings appears to be a dichotomy between secular school government activities on the one hand and religious activities on the other.

Factor 3 , young performers, appears to involve behavior settings where the performers are in the $2-11$ age range. In addition, the number of performers per occurrence had a relatively high loading on this factor. Thus, an important dimension of behavior settings appears to involve young performers functioning in relatively large groups. Interestingly, the education action pattern and the school authority system variable were not loaded on this factor, suggesting that young children engage in a substantial number of nonschool activities in which they are active performers. 


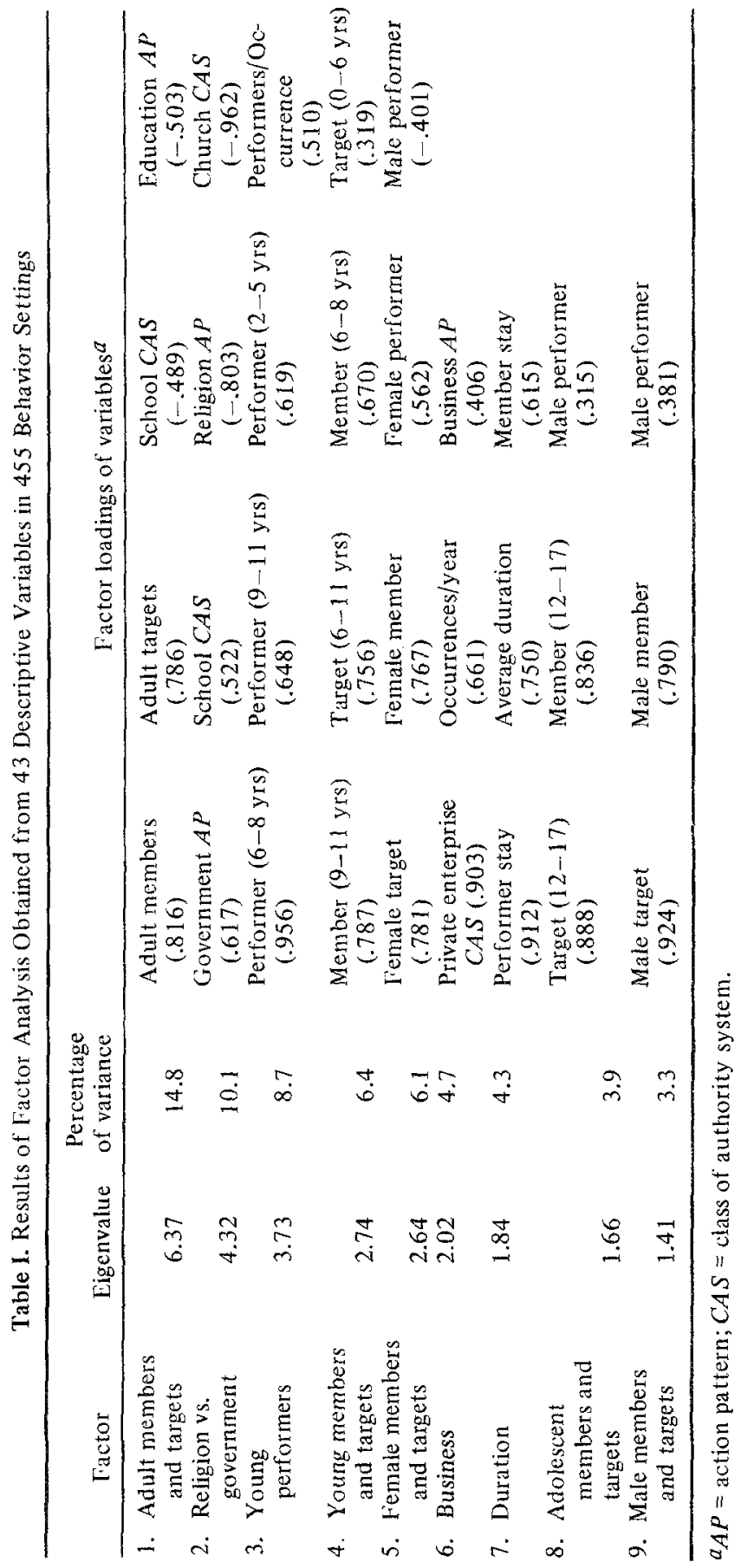


Factor 4, young members and targets, indicates that an important dimension of behavior settings involves the membership of children 11 years old or younger. Furthermore, the high loading on young target variables suggests that this factor involves settings which are especially intended for young children. It should be noted that all of the performer variables had negligible loadings on this factor, suggesting that age and sex of performers is widely distributed in settings especially intended for young children. Furthermore, the education action pattern and the school authority system variable both produced zero order loadings on this factor, indicating that many behavior settings especially intended for young children in the town are not necessarily conducted under the auspices of the school system.

Factor 5, female members and targets, had high loadings on female member characteristics and female target characteristics, indicating that this factor reflects settings especially intended for women. Female performer characteristics had a somewhat lower loading on this factor while male performers were quite unlikely to be represented, as indicated by the negative loading on this variable.

Factor 6, the business factor, was relatively homogeneous. The private enterprise authority system variable had an extremely high loading on this factor and the business action pattern variable also had a moderately high loading. Finally, quite plausibly, the business factor had the number of occurrences per year variable strongly associated with it. This is not surprising when one realizes that business enterprises are likely to be a type of behavior setting which occurs more frequently than others in a given town throughout a one-year period.

Factor 7 emerged as a clear-cut duration factor involving only the variables measuring the duration of behavior settings and the average stay of members and of performers. Thus, it seems clear that behavior settings vary to a substantial degree in their duration.

Factor 8 , adolescent members and targets, appears to reflect variation in behavior settings largely inhabited by and intended for the adolescent age group. The only other variable which loaded on this factor was that of male performers.

Factor 9, male members and targets, showed much the same pattern as Factor 5 did for females. High loadings of the male member and target variables and a moderate loading for the male performer variable suggests that a number of settings are run by, inhabited by, and intended for males in the town. It should be noted that Factor 5 and Factor 8 are not bipolar factors involving exclusively male or female status, but instead reflect variation in behavior settings that were either largely male or largely female. One can tentatively conclude that the town contains substantial numbers of behavior settings that are designed primarily for either females or males, but that there also exist large numbers of settings which are not exclusively male or female in nature. This latter conclusion is supported by the finding that the correlation between male and female membership variables was .25 even though clear male and female factors emerged in the factor analysis. 
The factor analysis yielded several interesting findings. First, the fact that age and sex variables frequently occurred in the factors obtained suggests that the average background characteristics of the inhabitants of behavior settings constitute a major dimension on which settings vary. Sells (1963) has included such age and sex characteristics as part of his extensive list of variables useful in characterizing environments. In addition, Moos (1973) has suggested that the average background characteristics of setting inhabitants constitute one possible approach to the description of environments. Indeed, Linton (1945) has observed that much of the social and cultural environment is transmitted through other people. This suggests that the character of a setting is dependent to a large degree on the typical characteristics of its members and that knowledge of the average background characteristics of setting inhabitants may allow inferences about the general character of the setting.

One additional in teresting implication of the rather clear emergence of age and sex characteristics in the setting factors obtained is that the characteristics of individuals and those of environments might be treated as commensurate dimensions. Thus, both individuals inhabiting the settings and the settings themselves could be characterized with respect to age and sex. The advantage of commensurate dimensions for both environments and individual inhabitants within them is that it provides a basis for assessing the degree of person environment congruence and its effects on behavior. Holland (1966) has suggested that the congruence or lack of congruence between setting characteristics and characteristics of individuals may affect important outcomes such as vocational achievement, satisfaction, and personal stability.

Although age and sex were dominant components of the factors extracted in the present analysis, they invariably emerged in combination with variables indicating the role of the inhabitant as member, performer, or target. This result suggests that Barker's inclusion of role status as a way of characterizing setting inhabitants is both useful and informative. The role designations of target and performer in particular help make explicit the potential socialization function of settings. Targets, it will be recalled, are those individuals for which settings are especially intended. Performer role variables not only provide information about the type of inhabitant within a setting who carries major responsibility for maintenance and continuity of a setting, but also suggest, as in Factor 3 for example, that the assignment of performer role to young persons can serve a specific training function and enhance the development of specific social skills and competence.

\section{STUDY II}

While the first study reported here focused on discovering the underlying dimensions along which behavior settings vary, the second study was directed at 
discovering empirically what types of settings exist in the town and the similarities and differences among them.

\section{Method of Analysis}

The classification of the 455 behavior settings was accomplished by conducting a cluster analysis of the settings based on their similarity with respect to the 43 variables originally used to measure setting characteristics.

The cluster analysis method used was MacQueen's K means analysis (MacQueen, 1967) adapted by Wishart (1972). The MacQueen solution initially partitions the entities to be clustered in to a specific number of $(\mathrm{K})$ clusters, randomly assigning entities to groups. Following the initial partition, the membership of the clusters is altered until a particular statistic is minimized. In the present analysis the statistic used was the error sum of squares within clusters (Ward, 1963). Thus, this statistic maximizes the homogeneity of clusters for a given value of $K$.

In the present study, four different initial random partitions at $K=20$ were used as separate replications of the analysis and solutions were obtained for $\mathrm{K}$ sizes ranging from 2 to 20 . The decision concerning the number of clusters to be examined was determined by finding the highest value of $\mathrm{K}$ at which the four replications were virtually identical. In the present analysis $\mathrm{K}=12$ produced virtually identical solutions.

\section{Results}

Table II lists the 12 behavior setting clusters obtained and the number of settings in each cluster. In addition, a homogeneity index is reported which reflects the degree to which the cluster is homogeneous with respect to the values of a given variable. The homogeneity index is the ratio of the standard deviation of a particular variable for the cluster under consideration to the standard deviation of the variable across all of the settings in the population. The homogeneity index is distributed approximately as $F$ and has an expected value of 1.0. Finally, a distinctiveness index is reported which reflects the degree to which the mean value of a given variable in the cluster under consideration differs from the mean value of that variable for all of the settings in the population. The distinctiveness index is the difference between the mean for a given variable in the cluster and the mean for that variable in the total population divided by the standard deviation of the variable for the entire population. The distinctiveness index is distributed approximately as $t$ and has an expected value of .0. High values of the distinctiveness index reflect relatively distinctive characteristics of the cluster. 
Table II. Results of Cluster Analysis of Behavior Settings

\begin{tabular}{|c|c|c|c|c|}
\hline Cluster & $N$ & Variable & Homogeneity & Distinctiveness \\
\hline $\begin{array}{l}\text { 1. Youth performance } \\
\text { settings }\end{array}$ & 14 & $\begin{array}{l}\text { Performers }(6-8) \\
\text { Performers }(9-11) \\
\text { Targets }(0-6) \\
\text { Targets }(6-11)\end{array}$ & $\begin{array}{l}.0001 \\
.0001 \\
.6474 \\
.0000\end{array}$ & $\begin{array}{l}5.61 \\
3.41 \\
1.39 \\
1.14\end{array}$ \\
\hline $\begin{array}{l}\text { 2. Religious } \\
\text { settings }\end{array}$ & 46 & $\begin{array}{l}\text { Church (CAS) } \\
\text { Religion }(A P)\end{array}$ & $\begin{array}{l}.0001 \\
.4100\end{array}$ & $\begin{array}{l}1.89 \\
1.86\end{array}$ \\
\hline $\begin{array}{l}\text { 3. Women's } \\
\text { organizational } \\
\text { settings }\end{array}$ & 29 & $\begin{array}{l}\text { Female target } \\
\text { Female performer } \\
\text { Male target } \\
\text { Male member } \\
\text { Male performer }\end{array}$ & $\begin{array}{l}.0000 \\
.0001 \\
.3967 \\
.2863 \\
.1425\end{array}$ & $\begin{array}{r}.33 \\
.58 \\
-3.01 \\
-2.44 \\
-1.23\end{array}$ \\
\hline $\begin{array}{l}\text { 4. Elementary } \\
\text { school } \\
\text { settings }\end{array}$ & 57 & $\begin{array}{l}\text { School }(C A S) \\
\text { Education }(A P) \\
\text { Targets }(6-11)\end{array}$ & $\begin{array}{r}.0702 \\
1.0184 \\
.2654\end{array}$ & $\begin{array}{l}1.11 \\
1.19 \\
1.00\end{array}$ \\
\hline $\begin{array}{l}\text { 5. High school } \\
\text { settings }\end{array}$ & 90 & $\begin{array}{l}\text { School (CAS) } \\
\text { Adolescent members } \\
\text { Adolescent targets }\end{array}$ & $\begin{array}{l}.2921 \\
.2181 \\
.0000\end{array}$ & $\begin{array}{l}.9853 \\
.9445 \\
.8256\end{array}$ \\
\hline 6. Adult settings & 36 & $\begin{array}{l}\text { Adult members } \\
\text { Adult targets }\end{array}$ & $\begin{array}{l}.0000 \\
.1121\end{array}$ & $\begin{array}{r}.82 \\
1.15\end{array}$ \\
\hline $\begin{array}{l}\text { 7. Men's organiza- } \\
\text { tional settings }\end{array}$ & 39 & $\begin{array}{l}\text { Male target } \\
\text { Male performer } \\
\text { Female members } \\
\text { Female targets }\end{array}$ & $\begin{array}{l}.0000 \\
.2082 \\
.4880 \\
.5449\end{array}$ & $\begin{array}{r}.3193 \\
.6640 \\
-2.6486 \\
-2.8431\end{array}$ \\
\hline $\begin{array}{l}\text { 8. Local business } \\
\text { settings }\end{array}$ & 40 & $\begin{array}{l}\text { Private enterprise ( } C A S) \\
\text { Occurrences/year }\end{array}$ & $\begin{array}{l}1.60 \\
.8707\end{array}$ & $\begin{array}{l}2.18 \\
2.25\end{array}$ \\
\hline $\begin{array}{l}\text { 9. Large } \\
\text { membership } \\
\text { settings }\end{array}$ & 7 & $\begin{array}{l}\text { Voluntary org. (CAS) } \\
\text { No. of members } \\
\text { Members }(0-1) \\
\text { Members }(2-5) \\
\text { Members }(6-8) \\
\text { Members }(9-11)\end{array}$ & $\begin{array}{l}.0001 \\
5.68 \\
.0001 \\
.0001 \\
.0001 \\
.0001\end{array}$ & $\begin{array}{l}2.15 \\
7.14 \\
2.05 \\
1.65 \\
1.21 \\
1.15\end{array}$ \\
\hline $\begin{array}{l}\text { 10. High school } \\
\text { performance } \\
\text { settings }\end{array}$ & 39 & $\begin{array}{l}\text { School (CAS) } \\
\text { Adolescent performers } \\
\text { No. of performers }\end{array}$ & $\begin{array}{l}.0001 \\
.5602 \\
1.43\end{array}$ & $\begin{array}{l}1.14 \\
1.33 \\
1.13\end{array}$ \\
\hline $\begin{array}{l}\text { 11. Family-oriented } \\
\text { settings }\end{array}$ & 40 & $\begin{array}{l}\text { Members }(2-5) \\
\text { Members }(6-8) \\
\text { Members }(9-11) \\
\text { Adult members } \\
\text { Targets }(0-6) \\
\text { Targets }(6-11)\end{array}$ & $\begin{array}{l}.6489 \\
.1971 \\
.0995 \\
.0000 \\
.7634 \\
.0992\end{array}$ & $\begin{array}{r}1.31 \\
1.11 \\
1.10 \\
.82 \\
1.31 \\
1.09\end{array}$ \\
\hline $\begin{array}{l}\text { 12. Government } \\
\text { settings }\end{array}$ & 17 & $\begin{array}{l}\text { Government (CAS) } \\
\text { Government }(A P)\end{array}$ & $\begin{array}{l}.0000 \\
.8454\end{array}$ & $\begin{array}{l}4.06 \\
1.41\end{array}$ \\
\hline
\end{tabular}




\section{Description of the Clusters}

Cluster 1, youth performance settings, was most clearly distinguished from other clusters by containing a number of settings with extremely large numbers of young performers. This cluster consists primarily of voluntary organizations. Typical examples of behavior settings included in this cluster are Christmas programs, Scout banquets, amateur talent shows, and mother-daughter banquets.

Cluster 2, religious settings, is distinguished primarily by a religious action pattern and membership in the church class of authority system. This cluster contained a vary large number of religion classes and worship services, and a moderately large number of church-sponsored activities, such as fellowship meetings.

Cluster 3, women's organizational settings, was characterized by a marked lack of male inhabitants and was composed of settings having female targets and performers. Typical behavior settings in this cluster included women's religious fellowships, sewing clubs, garden clubs, women's auxiliaries, and ladies' aid societies.

Cluster 4, elementary school settings, was distinguished from other clusters primarily by being intended for children in the 6-11 age range and being composed of settings in the school class of authority system. Although many of the settings were characterized by an educational action pattern, it also included settings which were not primarily educational in nature, including such typical settings as elementary school parties, kindergarten parties, and field trips.

Cluster 5, high school settings, was a relatively large cluster $(N=90)$ which, like the elementary school cluster just described, contained a large number of academic classes but also contained a substantial number of high school related activities. This cluster was composed almost exclusively of settings primarily intended for persons in the adolescent age range. Typical behavior settings in this cluster included high school classes, high school class trips, high school class club meetings, and high school dances.

Cluster 6, adult settings, is most clearly differentiated from other clusters by the fact that the membership in these settings is composed of and intended for adults to the exclusion of adolescents and children. Examples of settings in this cluster include PTA parent-teacher conferences, nursing home activities, county school administrators' meetings, electrical cooperative meetings, organized adult dinner parties, and teachers' meetings.

Cluster 7 , men's organization settings, was distinguished by a marked absence of female members or female targets, and by being exclusively intended for males. Typical behavior settings included meetings of church deacons, Kiwanis Club meetings, athletic banquets, and business meetings.

Cluster 8, local business settings, consisted almost entirely of local businesses. It was most clearly distinguished from other clusters by private enterprise 
authority system behavior settings, and by an extremely large number of occurrences per year. Typical behavior settings in this cluster include service stations, banks, barber shops, grocery stores, laundries, beauty shops, construction companies, lumber yards, and drug stores.

Cluster 9, large membership settings, was a small $(N=7)$ but homogeneous cluster of settings which was exclusively composed of voluntary organizations. These settings had extremely large numbers of members and relatively large numbers of young members and targets, and several of the settings had very long durations per occurrence. Interestingly, examination of the settings in this cluster indicated that virtually all of them are associated with an annual communitywide event participated in by large proportions of the population. The cluster includes such behavior settings as refreshment stands, street fairs, auto displays, machinery exhibitions, and a parade.

Cluster 10, high school performance settings, was composed almost exclusively of settings in the school class of authority system and displayed a predominance of performers in the adolescent age range. In addition, this cluster contained a large number of settings in which there were many performers per setting. Typical behavior settings contained in this cluster included school assemblies, graduation exercises, class plays and play competitions, athletic events, and homecoming parades and rallies.

Cluster 11, family oriented settings, was most clearly distinguished from other clusters by including members across the entire age range. A substantial number of the settings in this cluster were sponsored by voluntary organizations. Typical behavior settings in this cluster included picnics, dinners for the public, and family nights and bazaars.

Cluster 12, the final cluster, govemment settings, was characterized by settings falling exclusively within the government authority system. These settings largely involve government action patterns. Typical behavior settings in this cluster were township board meetings, elections and polling places, and city council meetings.

\section{DISCUSSION}

Taken together, the results of the two studies reported here provide a substantial amount of information concerning the dimensions along which behavior settings vary and the types of behavior settings that exist in the community under study. These two approaches to understanding the structure of the town dis. play a surprising amount of correspondence, although the factor analysis reflects similarities existing among measures used to characterize behavior settings while the cluster analysis reflects similarities among the settings themselves. 
Table III. Summary of Results of Factor Analysis of Behavior Setting Characteristics and Cluster Analysis of Behavior Settings

\begin{tabular}{|c|c|c|}
\hline & $\begin{array}{c}\text { Study I - Behavior setting } \\
\text { factors }\end{array}$ & $\begin{array}{c}\text { Study II - Behavior setting } \\
\text { clusters }\end{array}$ \\
\hline \multirow{9}{*}{$\begin{array}{l}\text { Results } \\
\text { corresponding } \\
\text { in both } \\
\text { studies }\end{array}$} & 6. Business & 8. Local business settings \\
\hline & 2. Religion vs. government & 2. Religious settings; \\
\hline & & 12. government settings \\
\hline & 3. Young performers & 1. Youth performance settings \\
\hline & $\begin{array}{l}\text { 4. Young members and } \\
\text { targets }\end{array}$ & 4. Elementary school settings \\
\hline & 8. Adolescent members and & 5. High school settings \\
\hline & 1. Adult members and tar- & 6. Adult settings \\
\hline & 5. Female members and tar- & 3. Women's organizational settings \\
\hline & 9. Male members and targets & 7. Men's organizational settings \\
\hline $\begin{array}{l}\text { Results } \\
\text { unique } \\
\text { to each } \\
\text { study }\end{array}$ & 7. Duration & $\begin{array}{l}\text { 9. Large membership settings } \\
\text { 10. High school performance settings } \\
\text { 11. Family-oriented settings }\end{array}$ \\
\hline
\end{tabular}

\section{Person-Environment Congruence}

A summary of the similarities and differences in the results of the two studies is given in Table III. Examination of Table III indicates that many of the setting types obtained in Study II are highly homogeneous with respect to the demographic and role characteristics of setting members. This in turn suggests that there exists a high degree of person-environment congruence (Pervin, 1968) in the present population of settings.

Although the phenomenon of person-environment congruence has been frequently observed, currently little is known about the processes by which persons select settings and settings select persons to produce the high degree of homogenity frequently found in social environments. Individual differences in personality may play an important role. For example, Eddy and Sinnett (1973) have found relationships between the personality characteristics of college students and the type of setting in which they spent their time. Interpersonal processes of the sort observed in the similarity and attraction literature (Byrne, 1971) may also contribute to the high degree of person-environment congruence. Finally, characteristics of settings themselves frequently serve the function of differentially selecting certain segments of the population for entrance into the setting (Barker, 1968).

The phenomenon of person-environment congruence is also important because of its apparent relationship to personal adjustment and adequacy of inter- 
personal functioning. For example, in a well-controlled study Wechsler and Pugh (1970) have found that psychiatric hospitalization rates are higher for persons whose in dividual demographic characteristics did not correspond with the overall demographic characteristics of the community in which they lived. Similarly, Pervin (1968) has shown that college dropout rates are higher for those students who displayed high degrees of incongruence between personal and college characteristics.

\section{Implications for a Theory of Settings}

Since the present results offer an empirical classification of settings, they may have implications for the development of an empirically based theory of social or community settings. Hempel (1965) has argued that classification may be thought of as a process of scientific concept formation where the classes derived represent the initial organizing concepts in a field of study. The present classification of social settings may thus provide hypotheses concerning the socialization, economic, political, and behavior control functions of social settings in the context of an entire community.

There exist some interesting correspondences between the results of the present analyses and other attempts to offer broad classifications of organizations or settings. For example, Parsons (1956) has classified organizations according to the social needs to which the organizations are directed and, therefore, has divided organizations into (1) those which are oriented toward economic production, (2) those oriented toward political goals, (3) those primarily concerned with social integration, and, (4) those concerned with pattern maintenance.

It could be tentatively suggested that Parsons' economic production category is similar to the present local business settings cluster. Parsons' category describing political organizations corresponds to our government settings cluster. In addition, a number of setting clusters appear to be concerned with social integration, in particular, youth performance settings, elementary school settings, and high school settings, while the religious settings cluster might be thought of as involving pattern maintenance in the context of Parsons's system.

\section{Implications for Research}

Finally, because the present studies are based on the entire population of behavior settings in the community under study, the results may be of considerable use to researchers interested in studying the impact of situational variables on individuals, especially in rural field settings. For example, the results of the 
factor analysis in Study I suggest that a relatively few attributes or dimensions may be particularly useful in describing settings. Thus, a factorially derived descriptive measurement instrument can be developed from the results of Study I that would provide researchers with a standard and economical instrument for measuring the dimensions along which settings vary.

Perhaps more important, the setting clusters obtained in Study II may provide an empirical basis for selecting a stratified sample of settings in new communities with some assurance that the settings selected represent distinctive and important setting types.

\section{REFERENCES}

Astin, A. W. An empirical characterization of higher educational institutions. Journal of Educational Psychology, 1962, 53, 224-235.

Bailey, K. D. Monothetic and poly thetic typologies and their relation to conceptualization, measurement and scaling. American Sociological Review, 1973, 38, 18-33.

Barker, R. G. Ecological psychology: Concepts and methods for studying the environment of human behavior. Stanford, California: Stanford University Press, 1968.

Barker, R. G., \& Gump, P. V. Big school, small school. Stanford, California: Stanford University Press, 1964.

Blashfield, R. K. An evaluation of the DSM-II classification of schizophrenia as a nomenclature. Journal of Abnormal Psychology, 1973, 82, 382-389.

Byrne, D. The attraction paradigm. New York: Academic Press, 1971.

Cattell, R. B. The SCREE test for the number of factors. Multivariate Behavioral Research, $1966,1,245-276$.

Cowen, E. Social and community interventions. Annual Review of Psychology, 1973, 24, 423-472.

Craik, K. H. Environmental psychology. Annual Review of Psychology, 1973, 24, 403-422.

Eddy, G. L., \& Sinnett, E. R. Behavior setting utilization by emotionally disturbed college students. Journal of Consulting and Clinical Psychology, 1973, 40, 210-216.

Frederiksen, N. Toward a taxonomy of situations. American Psychologist, 1972, 27, 114-123.

Hempel, C. G. Aspects of scientific explanation. New York: Free Press, 1965.

Holland, J. The psychology of vocational choice. Waltham, Massachusetts: Blaisdell, 1966.

Linton, R. The cultural background of personality. New York: Century, 1945.

MacQueen, J. Some methods for classification and analysis of multivariate observations. In L. M. Lecam \& J. Neyman (Eds.), Proceedings of the Fifth Berkeley Symposium on Mathematical Statistics and Probability, 1967, 1, 281-297.

Mischel, W. Towards a cognitive social learning reconceptualization of personality. Psychological Review, 1973, 80, 252-283.

Moos, R. H. Conceptualization of human environments. American Psychologist, 1973, 28, 652-665.

Nie, N. H., Bent, D. H., \& Hull, C. H. Statistical package for the social sciences. New York: McGraw-Hill, 1970.

Parsons, T. Suggestions for a sociological approach to the theory of organizations. Administrative Science Quarterly, 1956, 1, 63-85.

Pervin, L. A. Performance and satisfaction as a function of individual-environment fit. Psychological Bulletin, 1968, 69, 56-68.

Price, R. H. The taxonomic classification of behaviors and situations and the problem of behavior-environment congruence. Human Relations, 1974, 27, 567-585. 
Price, R. H., \& Bouffard, D. L. Behavioral appropriateness and situational constraint as dmensions of social behavior. Journal of Personality and Social Psychology, 1974, 30, 579-586.

Price, R. H., \& Moos, R. H. Toward a taxonomy of inpatient treatment environments. Journal of Abnormal Psychology, 1975, 84, 181-188.

Sells, S. B. (Ed.). Stimulus determinants of behavior. New York: Ronald Press, 1963.

Ward, J. H., Jr. Hierarchical grouping to optimize an objective function. Journal of the American Statistical Association, 1963, 58, 236-244.

Warriner, C. K., \& Prather, J. E. Four types of voluntary associations. Sociological Inquiry, $1965,35,138-148$.

Wechsler, H., \& Pugh, T. F. Fit of individual and community characteristics and rates of psychiatric hospitalization. In H. Wechsler, L. Soloman, \& B. M. Kramer (Eds.), Social psychology and mental health. New York: Holt, Rinehart \& Winston, 1970.

Wicker, A. W. Processes which mediate behavior-environment congruence. Behavioral Sctence, 1972, 17, 265-277.

Wishart, D. CLUSTAN I. B. London: London University Computation Center, 1972. 